\title{
A Portable Electronic Transaction Device Based on Dual Interface Smart Card
}

\author{
https://doi.org/10.3991/ijoe.v16i03.11639 \\ Syifaul Fuada $\left({ }^{\square}\right)$ \\ Universitas Pendidikan Indonesia, Pendidikan, Indonesia \\ syifaulfuada@upi.edu \\ Akhmad Alfaruq, Trio Adiono \\ Institut Teknologi Bandung, Bandung, Indonesia
}

\begin{abstract}
In recent years, electronic money facilities are increasingly diverse. It may replace conventional payments. The use of physical money can be diminished by utilizing digital money, which is realized by smartphone apps, bar codes, smart cards, and so on. The types of smart cards used also vary, and it can be divided into two methods, i.e., with contacts and without contact. In this work, we develop electronic transaction devices using dual interfaces: contact and contactless smart cards. As computational processing, we employ the Raspberry Pi 3 Model 3. It has a high processing speed, large memory, and small size. Hence our system enables to compact in a portable box. The features offered on our transaction device are as follows: transaction menu, balance check menu, payment menu, and top up menu. Also, we provide a device transaction connection to the printer. Therefore, proof of transactions can be printed out easily. The device developed also provides a touch panel display to display the transaction menu.
\end{abstract}

Keywords-Smart card, contactless and contact smart card, electronic transaction device

\section{Introduction}

The rapid development of information technology has a significant impact on human lifestyles. In Indonesia, this progress provides various facilities, one of which is the payment mechanism. The use of electronic money can increasingly replace regular payments. Electronic money offers many features and eases to use for transactions. Indonesia government regulation also triggers on the demand for electronic money, ex. Payment transactions on the highway, public transportation, and toll road that are required to use smart card contact.

In 2017, the volume of transactions using electronic money was recorded at $943,319,933$ transactions with a nominal value of 12.375 trillion rupiahs. This number increased compared to 2016, which amounted to $683,133,352$ transactions with a nominal value of 7.063 trillion rupiahs [1]. As of December 2019, there are 35 com- 
panies registered at Bank Indonesia (BI) [2]. This fact shows that there is an excellent opportunity for companies to open up participation and competition in electronic money-based businesses.

There are several payment methods support transactions using existing electronic money, including Debit cards, Credit cards, E-wallet, Smart card, and Wireless payment. Based on the technology used, it can be divided into two types of electronic money, namely Chip-based and server-based. Chip-based electronic cash is realized with a non-touch mechanism card, which is then called as a "smart card". Whereas, Server-based digital money (E-wallet) generally uses applications on smartphones as media transactions such as T-cash, Go-pay, i.Saku, Sakuku, LinkAja, DOKU, Dana, OVO, and so on. The e-Wallet has disadvantage, e.g. the digital money only applies to specific merchants. Their services only for partner merchants. So, if the transaction is not with their partner, we must use another payment method. Another drawback is it depends on the internet network.

Chip-based, server-based, or combination of both are the most widely used for electronic money transactions nowadays, especially in Indonesia. This condition encourages researchers and application designers in developing electronic payment systems with high-flexibility, fast data processing, user friendly, and it has a good performance (high-reliability). The existence of smart cards has received special attention since the last two decades. This embedded chip card has been widely used for various access applications. Research on the use of smart cards as electronic transactions have been carried out in [3-4], they implemented at System-On-Chip Zynq-700. Furthermore, media access control for security has been conducted, as in [5-9]. In [10], the RFID-based smart cards for goods locator applications have also been implemented. RFID-based contactless card has been proposed in [11-14] as a medium for electronic money transactions. However, In Ref [11-14] have not been equipped with the following features: payment, balance check, and top-up on single board computers. In Indonesia, many people have become users of smart contact and contactless smart cards. Thus, its penetration as a payment medium will increase significantly for the coming years.

The commercial electronic transaction devices have been found in cashiers of modern shops, minimarkets, or supermarkets. They have used this device to receive non-cash payments from a smart card by inserting it, as shown in Fig. 1a. Moreover, there is a contactless device as shown in Fig. 1b (using Dana E-wallet device). However, it is still rarely found electronic transaction devices with dual interfaces. Therefore, the motivation of this work is to design and develop an electronic device with dual-mode that ready to mass-market. The technology adopted of the developed device is based on single-board computers. Electronic transaction devices as visualized in Fig. 1(a) cannot be applied at other applications like toll payment devices, as shown in Fig. 1(c), because in Indonesia, most of toll payment devices use the contactless smart card method. As such, our system can later be applied anywhere and for any payment application. That is why the two-payment mode is necessary. 


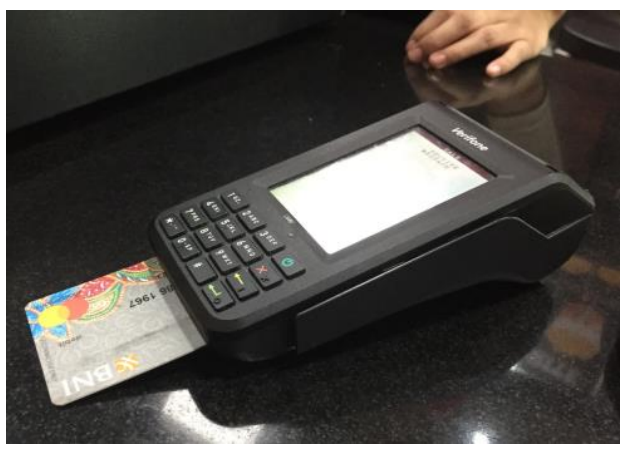

a)

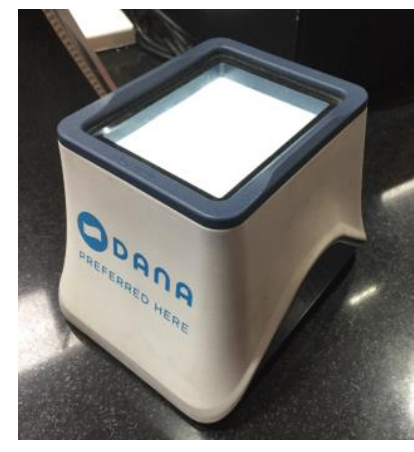

b)

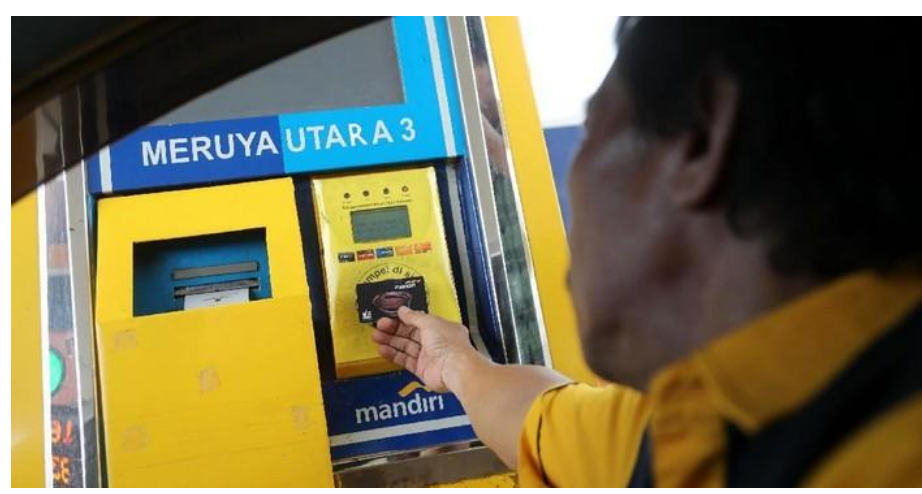

(c)

Fig. 1. Commercial device of portable electronic transaction: (a) contactless; (b) contact smart card; (c) toll payment device that uses a contactless smartcard

Two payment methods, using contacts \& contactless smart cards, are implemented on our system. It can be used to pay, refill (top-up) money, and check balances on minicomputers that are integrated with online database servers. Other features offered are $\mathrm{Wi}-\mathrm{Fi}$, print receipts, and payment list updates.

Later, this portable transaction device will be applied in Institut Teknologi Bandung (ITB) campus, integrated with other services within ITB environment, e.g. ITB's smart canteen, ITB's parking system, and ITB's bike sharing system as elaborated in [15] and so on. Contact and contactless smart card will also be realized by ITB's student identification card. 


\section{System Design}

\subsection{System Block}

The whole system can be seen in Fig 2. It consists of three main parts, namely the hardware, software, and server. The system has specifications as follows:

- It can perform balance check, top-up, and payment transactions

- Contact, and contactless-type smart cards can access it

- User interface using an LCD touchscreen

- It can print the transaction proof by a thermal printer

- The transaction history is recorded on the server. In this paper, we focus on point 1 to point 4 . We will expand the content of this paper which covers point 5 in further publication.

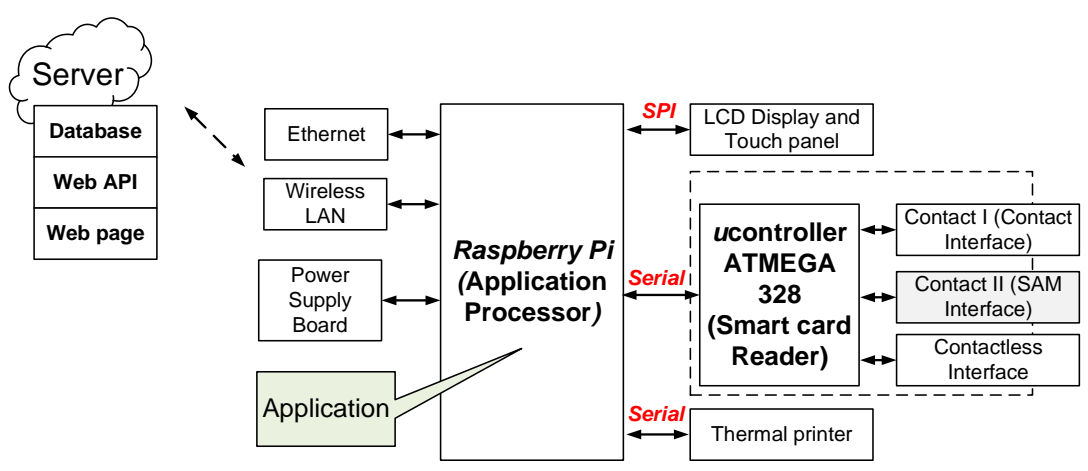

Fig. 2. Block diagram of a portable electronic transaction system

\subsection{Operation procedure of smart card}

The communication between reader to the Smart card need several procedures as shown in Fig. 3. Smart card contact has various types, an A-class smart card works at 4.5 to $5.5 \mathrm{~V}$ with $60 \mathrm{~mA}$ of maximum current. Then B-class and C-class operate at 2.7 to $3.3 \mathrm{~V}$ and 1.62 to $1.98 \mathrm{~V}$ with maximum current about $50 \mathrm{~mA}$ and $30 \mathrm{~mA}$, respectively. At the first step, the smart card reader will determine the required operating voltage.

Further, the smart card will do following tasks: activate, cold reset, or warm reset. The operating voltage starts from the lowest to the highest voltage. This procedure must be done so the reader does not damage the card due to overvoltage. If the smart card supports that voltage class, it will respond "answer to reset" (ATR). While if the smart card does not send ATR, meaning that it does not support the used voltage class.

The following are the activation procedure: firstly, adjust the reset pin in the low state, then turn on the VCC. The I/O pin is set in the position of receiving data, and 
the clock pin is triggered by a clock signal starting at Ta point. The Cold reset can be done by keeping the reset pin at a low state on initial activation, about $\sim 400$ cycles (delay tb) which are calculated from the Ta point. Then the reset pin is set in a high state at Tb point. After that, the smart card will respond between 400 to 40,000 clock cycles. If the smart card does not answer within this period, the reader will deactivate it. The deactivation process starts by setting the reset pin in the low point, turning off the clock signal, and the last step is turning off the VCC. Due to the reset signal is in low state, the signal on the $\mathrm{I} / \mathrm{O}$ pin will be ignored. The activation and deactivation process timing diagram can be seen in Fig. 4(a) and Fig. 4(b), respectively.

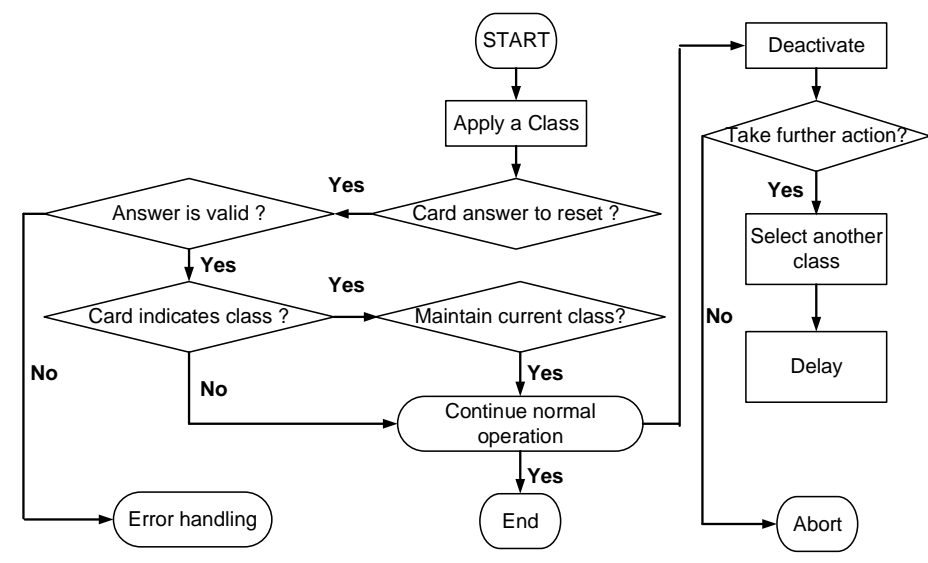

Fig. 3. Procedure for class selection on a smart card

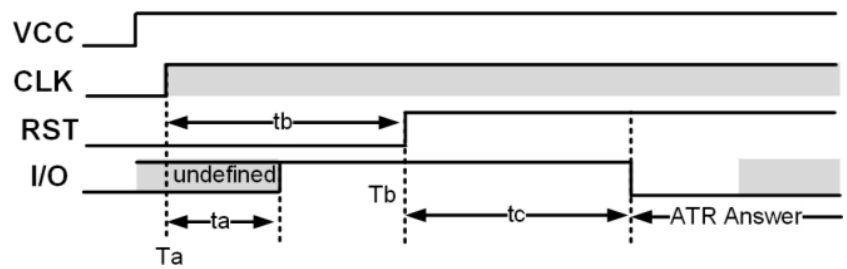

(a)

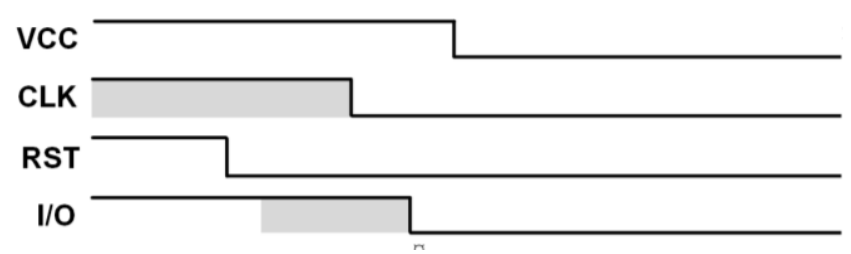

(b)

Fig. 4. Timing diagram of: (a) activation and cold reset processes; (b) deactivation process on the smart card 


\subsection{Data transmission on smart card}

The data communication between the reader and smart card is serial in a bitstream form that is represented by high states and low states. While the voltage level used is corresponded the required voltage class, namely $\pm 5 \mathrm{~V}, \pm 3 \mathrm{~V}, \pm 1.8 \mathrm{~V}$ with $0 \mathrm{~V}$ as the reference voltage. In direct conventions, the high state is represented by a higher voltage $( \pm 5 \mathrm{~V}$ or $\pm 3 \mathrm{~V}$ or $1.8 \mathrm{~V})$, while $0 \mathrm{~V}$ represents the low state. Whereas in reverse conventions do the opposite.

Elementary Data Unit (ETU) is the width for one bit of data. The ETU value is determined by the ratio of $\mathrm{F}$ per $\mathrm{D}$ multiplied by the clock cycle. $\mathrm{F}$ is the clock rate conversion integer, while $\mathrm{D}$ is the baud rate adjustment integer. Both $\mathrm{F}$ and $\mathrm{D}$ values can be obtained from information in ATR. At the beginning of communication, ETU values are determined as 372/f second, where $\mathrm{f}$ is in Hertz.

Character sending between a reader and a smart card contains 10 bits data, which can be high or low. Before the sending data process, the I/O pin condition must be in high state. The process starts with sending "start bits" as the first bit, which is low conditioned. Then proceed with sending 8 bits data (the second bit to ninth bit), the last is the parity bit (10 bits). The parity value for each bit must be not odd (even), which means if the number of bits 1 in the data is odd, then the parity value is 1 . And if the number of bits 1 in the data is even, the parity value is 0 . After sending the tenth bit, the I/O pin will remain in high state for 2 ETU before being ready to send the next character. The character frame format is illustrated in Fig. 5.

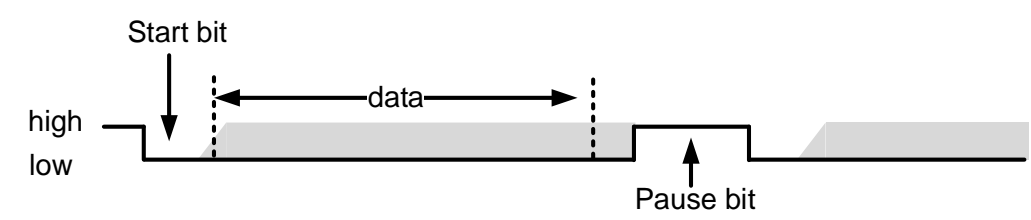

Fig. 5. Data frame character of communication between the smart card reader and smart card

\subsection{Hardware design}

As in Fig. 2, the smart card reader hardware can be divided into five primary parts, i.e., power supply board, single board computer (SBC), LCD display and input, reader module, and printer. We used Raspberry Pi 3 Model B as SBC (application processor), functioned to run the electronic transaction program. Raspberry Pi has complete features, such as USN, serial, SPI, Ethernet, Wi-Fi and GPIO extender. In this work, Ethernet and $\mathrm{Wi}-\mathrm{Fi}$ connections were used for connecting a reader device to the server through the internet. USB and serial connections were applied for interfacing the reader device to printers and smart cards, respectively. The SPI connection was used as data communication between the reader device to an LCD \& touch panel module, while the GPIO pin functioned to detect whether the reader device was connected to an electrical input or not. To display and enter the character, we used an LCD module \& 3.5 Inch touch panel. The hardware of smart card reader device is depicted in Fig. 6. 


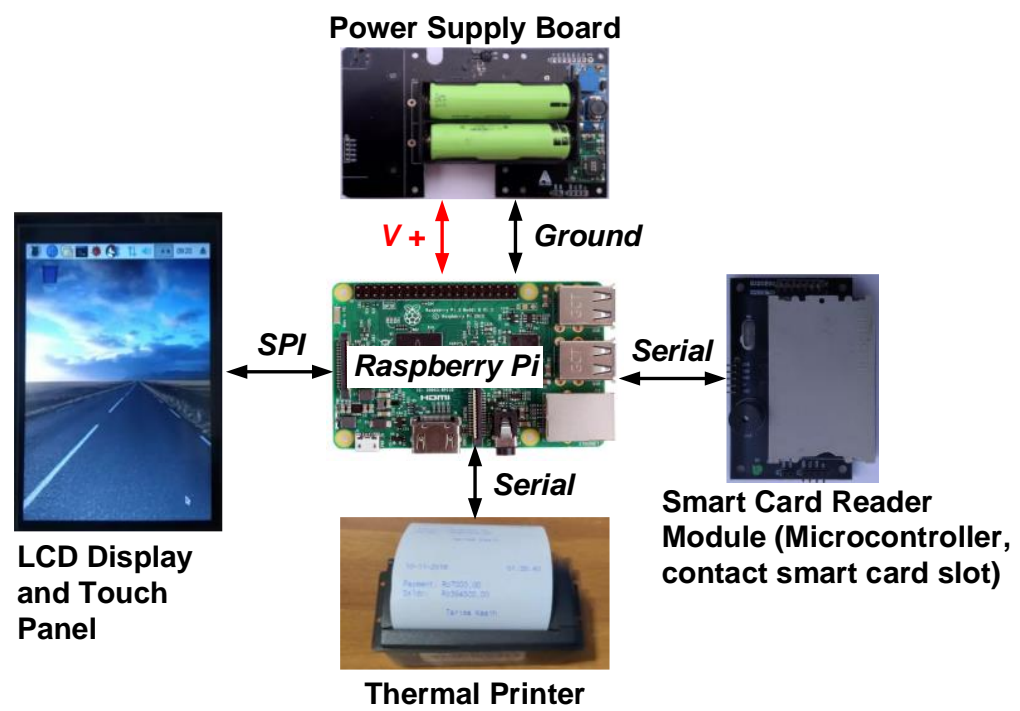

Fig. 6. Hardware design of electronic transaction devices based on contact and contactless smart card

Power supply board, as shown in Fig. 7 was designed to provide a safe power supply for all circuits. There are three loads in the reader device that must be powered properly: SBC, smart card reader, and printer. However, the power supply for the printer is developed separately because its input voltage varies, ranging from $5 \mathrm{~V}$ to $12 \mathrm{~V}$ with a relatively high current requirement. Moreover, we also provide battery backup in our board.

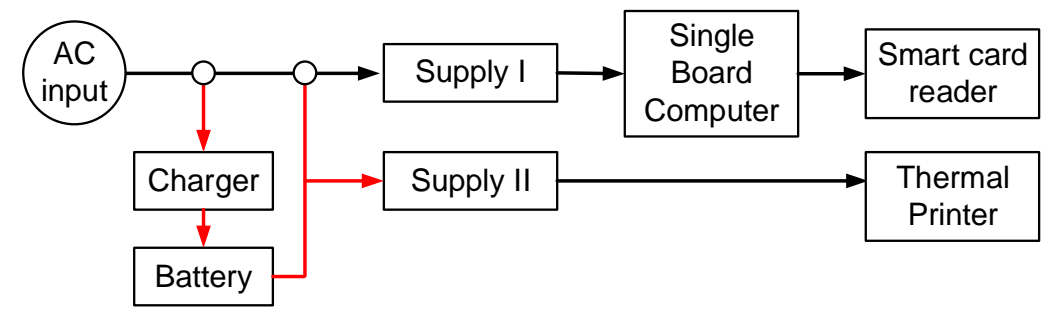

Fig. 7. Block diagram of power board

The reader device was employed to read contact and contactless smart card. The contact smart card refers to the ISO/IEC 7816 whereas contactless smart card refers to the ISO/IEC $14443 \mathrm{~A} / \mathrm{MIFARE}$ standard. In the smart card reader device, there are three types of interface, namely contact, Secure Access Module (SAM), and contactless interfaces. We used Microcontroller ATMega 328 as pin signal controller in the contact and SAM interfaces. To control the signal on the contactless interface, we used MFRC522. 


\subsection{Application design}

The application has functioned as a graphical user interface. It was used to control the components in the reader device. Thus, it can work correctly, as expected. Controlled components include a smart card reader, LCD display, and printer. The application also handles input received through the touch panel. To be easy to operate the application, a menu layout and good input handlers need to be realized.

The layout on the LCD screen as visualized in Fig. 8(a), was divided into three sections, namely:

- Toolbar

- Body

- Navigation

The toolbar section contains hours \& dates, the status of the charger, battery, and wireless LAN connection while the body section includes menus that will be displayed by LCD screen and then operated (selected) by the users. Three transaction menus will be displayed, namely, balance check, payment, and top-up menus. Besides three transaction menus, as mentioned before, a configuration menu is also involved (Fig. 8b) in managing wireless LAN, printer, and partner list. Application must be able to access console on Linux. In this work, we used Qt library to develop applications.

Qt is a free and open-source widget toolkit to develop GUI that run on various operating systems or embedded systems. By using Qt, special libraries also can be created, ex. interface library to a charger, Wi-Fi network, thermal printer, smart card read$\mathrm{er}$, and ADC reader feature. The charger library uses for interfacing the reader device to the charger board. Thus, the inputted power to the smart card reader device can be detected correctly. Considering this condition, we need two GPIO pins (for input and output) taken from the 40 pins GPIO extended on the Raspberry Pi.

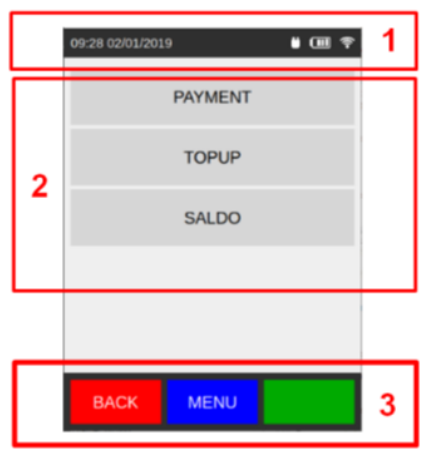

(a)

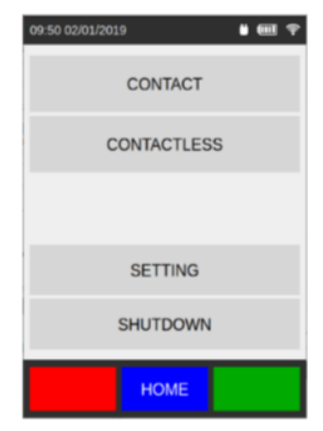

(b)

Fig. 8. Application interface: (a) the layout on the LCD display containing transaction menus; (b) main menu 


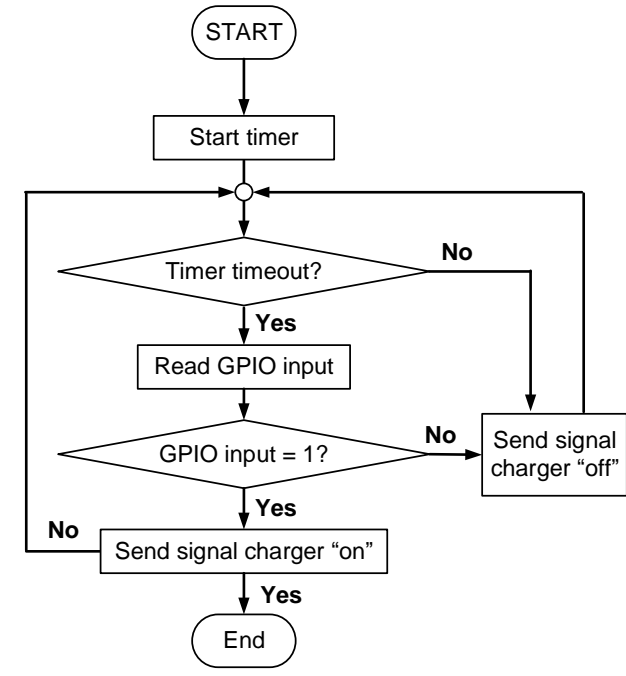

(a)

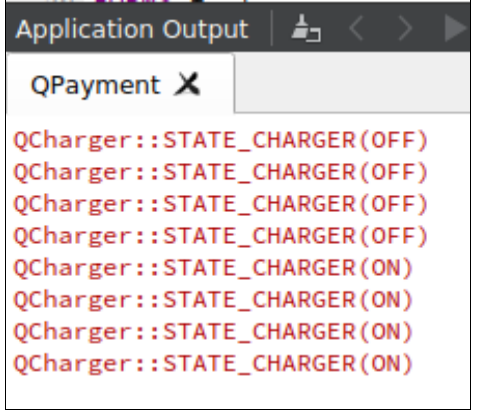

(b)

Fig. 9. Charger library: (a) flowchart; (b) output

The two GPIO pins are then connected to a relay that already connected to the charger line. If the charger is "on" position, the GPIO input \& output is connected so that the input pin will be read as state high. It indicates that the charger is on. If the charger is "off" position, the relay disconnects the connection between the GPIO input \& output, so the input reads state low. In this library, a timer is created to check the result every three seconds and send it, in the form of Signals \& Slots, which is a communication mechanism in Qt. To test this library, we used a debug function found in Qt in which the workflow is depicted in Fig. 9(a). Based on the test results, as shown in Fig. 9(b), the library has appropriately functioned as expected. When the charger is turned off, the state becomes off and vice versa.

The network library was used for substituting the wireless LAN configuration on the reader device. The developed application requires an access to the Linux console, this configuration is done using the command on Linux console, wpa_cli -i wlan0 reconfigure. Before calling the command reconfigure, we need to create a file wpa_supplicant.conf which contains the name SSID and key. Before the file is created, turn off the network with the ifconfig wlan0 down command, then turn it "on" again with the ifconfig wlan0 up command.

The Smart card Library was used to handle the data exchange between the smart card reader and the Raspberry Pi. All actions done by the application are translated to the command on the reader module. And all responses sent from the reader module are translated into Signals \& Slots. The printer library was used to create data formats (such as the align used, font size, and font style) to be printed out using a thermal printer. 


\section{$3 \quad$ Results and Analysis}

\subsection{Implementation}

A photograph of portable electronic transaction device is visualized in Fig. 10. It has a weight of 128.58 gram, and $\mathrm{L} \mathrm{x} \mathrm{W} \mathrm{x} \mathrm{H} \mathrm{of} 161 \mathrm{~cm}$ x $85 \mathrm{~cm}$ x $62 \mathrm{~cm}$, respectively. The casing of portable transaction device is implemented using 3-Dimension printing with Polylactic Acid (PLA) material.

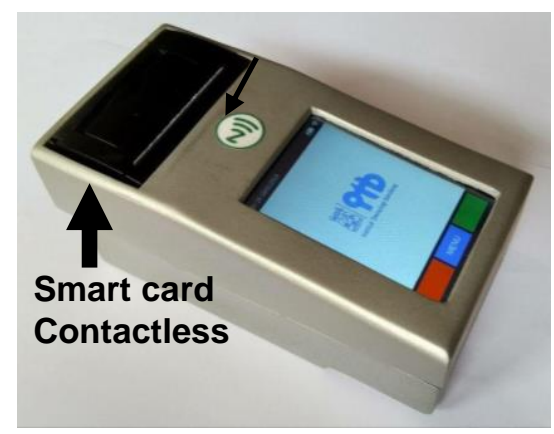

(a)

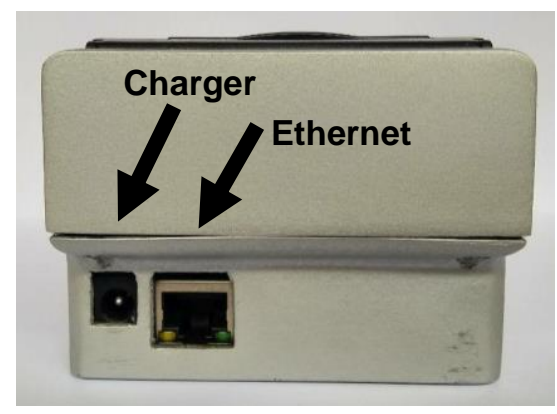

(c)

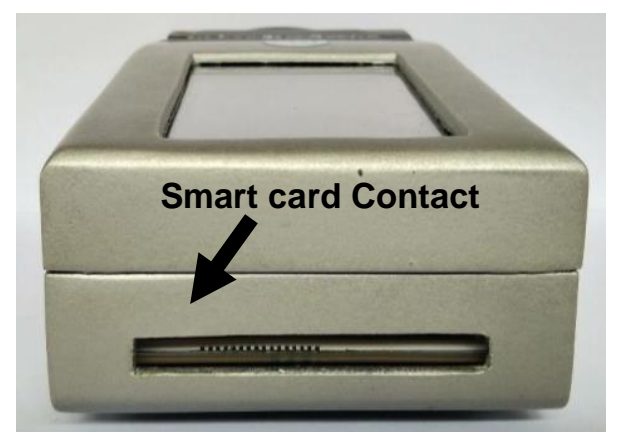

(b)

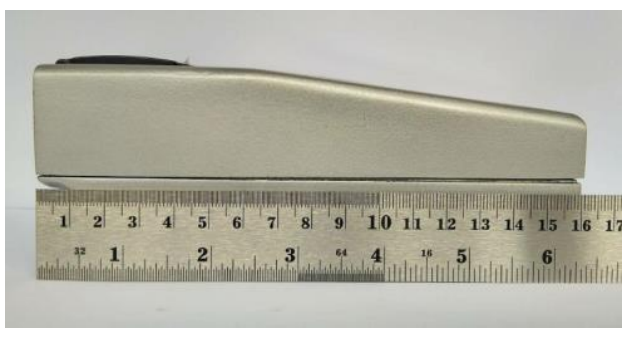

(d)

Fig. 10. The appearance of a portable electronic transaction device: (a) complete system [16]; (b) top view; (c) bottom view; (d) device dimension

\subsection{Smart card operating procedure}

After the hardware and firmware are realized, the next step is to evaluate the smart card reader. First, we test it using contact smart card type. The Answer to Reset (ATR) data will start sending after the smart card reader has activated and cold reset. Fig 11(a) is the signal reading results from the logic analyzer for contact I interface. 


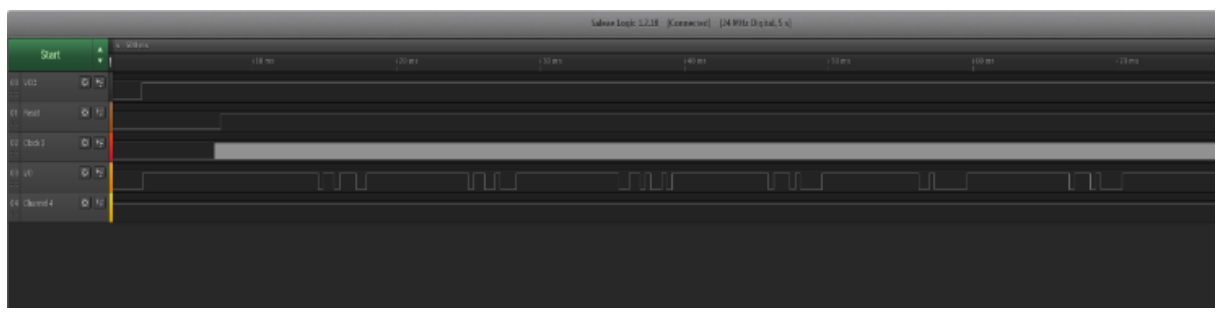

(a)

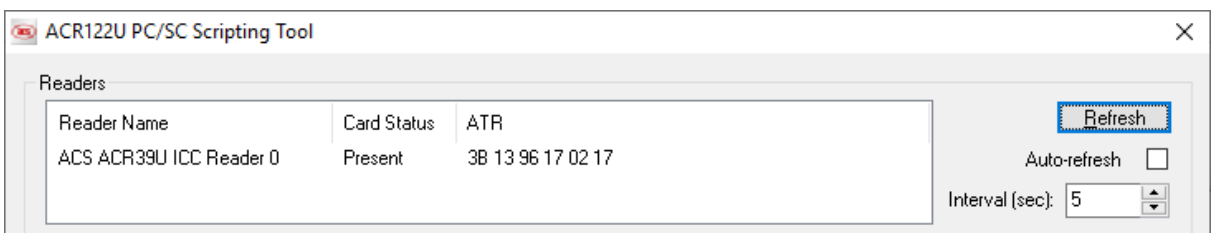

(b)

Fig. 11.The ATR signal received by the smart card reader: (a) on contact interface; (b) using ACR39U reader; (c) on SAM interface

From these signals as in Fig. 10(a) are then converted to bit streams (1 and 0 logics). By using the ETU calculation formula, we obtain clock cycles as follow: $1 \mathrm{ETU}=\frac{\mathrm{Fi}}{\mathrm{Di}}=\frac{372}{1}=372$ clock cycles. The conversion results are then separated between start bit, data, CRC, and pause bits. Thus, the actual data is obtained. Further, the obtained data are then converted to hexadecimal, so that the ATR value obtained is 3B 13961702 17, as shown in Fig. 11(b). To validate these results, the smart card is tested on the ACR39U reader. The SAM interface (contact II) test also using the same method, the logic analyzer test of SAM interface can be seen in Fig. 11(c) that is similar to the simulation result on contact I. Based on the test results, it was found that the reading of the ATR value on contact I and contact II interface was correct.

\begin{tabular}{|c|c|c|c|c|c|}
\hline & & & Colors\&Fonts Mode & $\mathrm{COM} 7$ & 115200 , None, 8,1 \\
\hline \multicolumn{6}{|l|}{ Communication } \\
\hline ASCII $\mid$ HEX $\mid$ & Decimal| & Binary & & & \\
\hline $\begin{array}{l}07 / 01 / 2019 \\
07 / 01 / 2019\end{array}$ & $\begin{array}{l}08.39 \\
08.39\end{array}$ & $\begin{array}{l}.00 .673[\mathrm{TX}] \\
.00 .755[\mathrm{RX}]\end{array}$ & $\begin{array}{lllll}-5130 & \text { D0 } & 01 & 0 \\
-5130 & 90 & 00<0\end{array}$ & $\begin{array}{l}5130 \quad 30 \\
\langle\mathrm{LF}\rangle\end{array}$ & $\begin{array}{lll}30 & 30 & 31\end{array}$ \\
\hline
\end{tabular}

(a) 


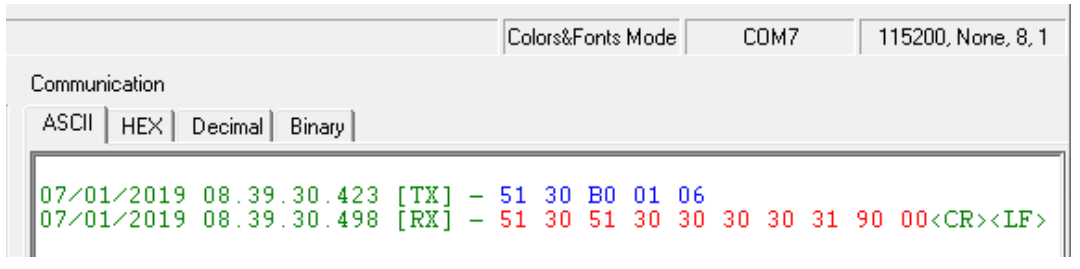

(b)

Fig. 12.The results of: (a) writing data and (b) reading data on contactless type smart cards using the proposed smart card reader

Later, we evaluate the read and write mechanism of contactless-type smart cards. The procedure used is the same as the contact type smart card test, which is writing data to the smart card (shown in Fig. 12a) and then reading it and comparing the results. In this test, the written data is stored in sector I. The test result of the reading mechanism on contactless smart cards can be seen in Fig. 12(b). To prove it, we test reading smart card by using a cellular telephone with an android OS that supports NFC. We use a specific application provided by NFC Tools. The reading results using NFC Tools can be seen in Fig. 12, it shows that the data sector 1 at the initial 6 bytes is 5130303030 31, which is similar to results depicted in Fig. 12(a) and Fig. 12(b), i.e., 5130303030 31. It proves that the smart card reader on contactless-type is functioning correctly.

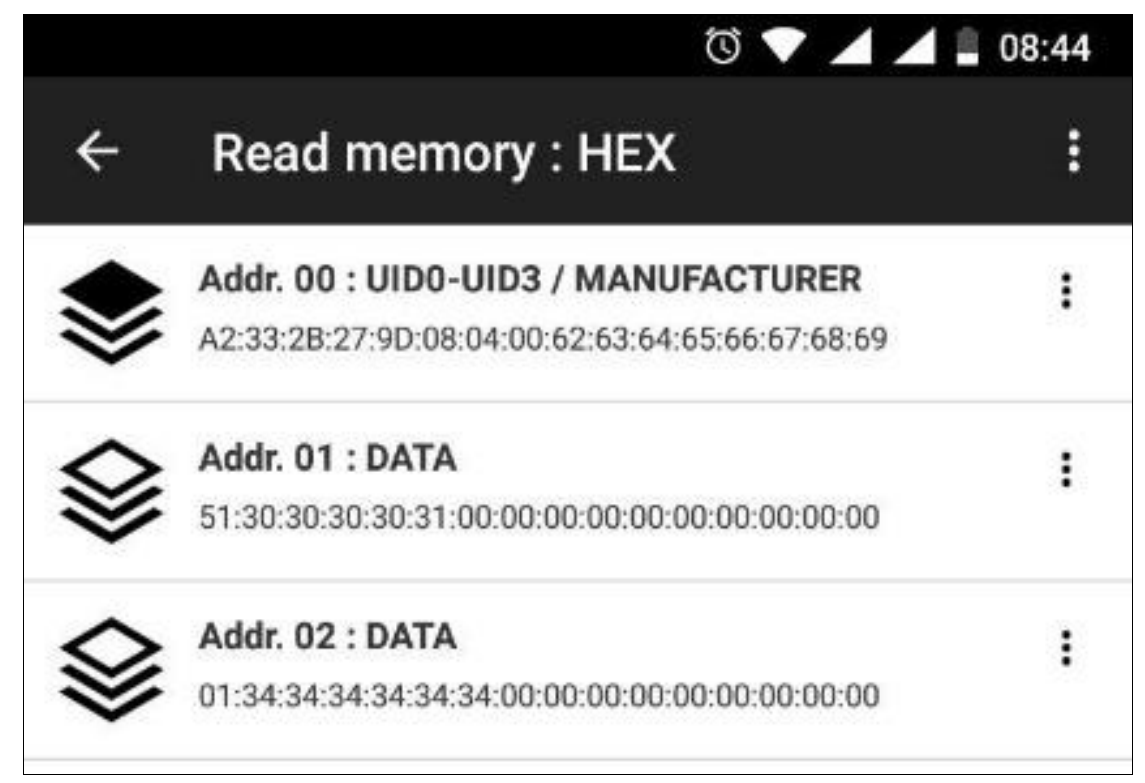

Fig. 13. Smart card reading results using the NFC Tools application 


\subsection{Functional testing}

The balance check menu is used to display the nominal balance on contact and contactless smart cards. The flow chart of the balance check process can be seen in Fig. 14. To make it easier to operate, we added several guide menus, as shown in Fig. 15(a) and Fig. 15(b) for contact and contactless type of smart cards, respectively.

The first step to check balances is to open the main menu, then select the smart card types. If the type of smart card is contact, put it in the provided slot. If the contactless smart card type, then attaches/tap it at the provided spot. If the smart card is successfully read, the balance will be displayed on the LCD screen as visualized in Fig. 15(c).

Users can select the payment menu to make payments using a smart card. The first step in the payment process is to open the main menu, then select the type of smart card used. This menu also displays a list of partners registered with the device. If the business partner is not yet recorded, we can make a payment by entering the partner ID manually. The complete payment process is illustrated in Fig. 16.

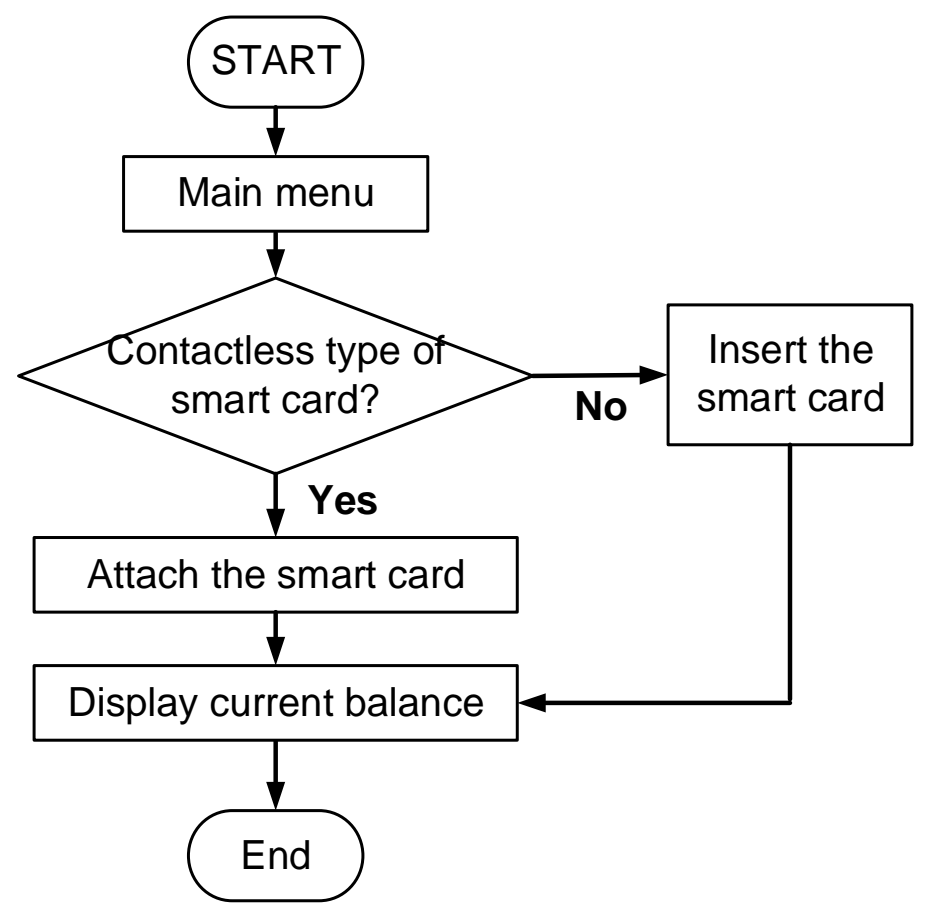

Fig. 14. Flowchart of balance checks on contact and contactless smart cards 


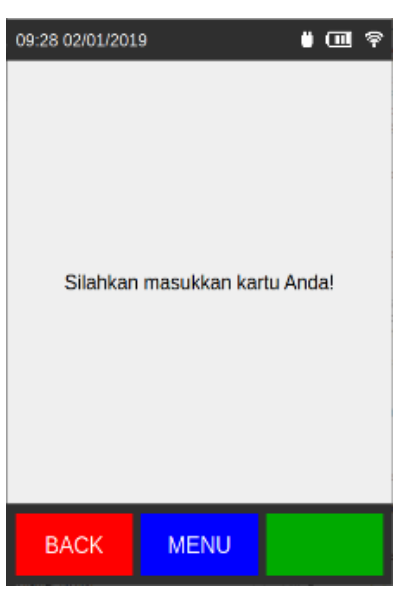

(a)

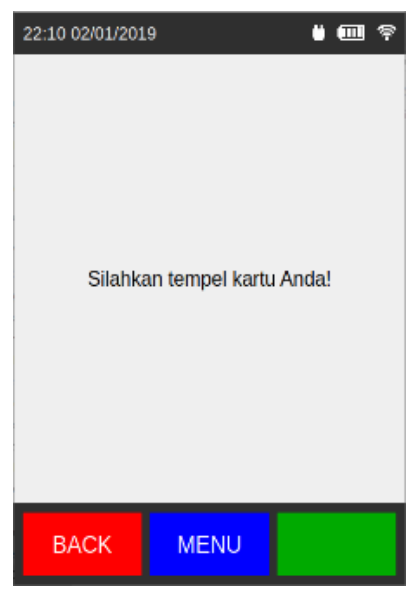

(b)

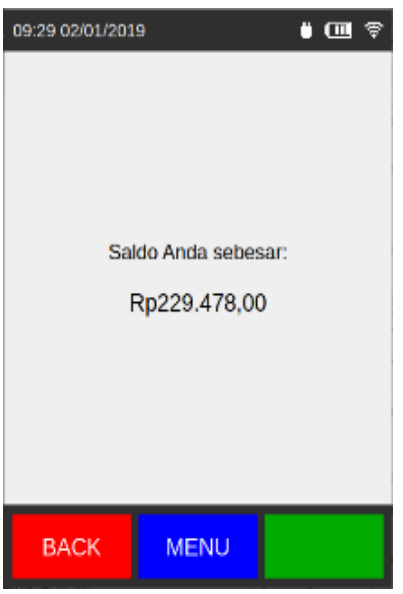

(c)

Fig. 15.The appearance of balance check menu on the card reader application: (a) a guide on contact smart card "please insert your card"; (b) a guide on contactless smart card "please attach your card"; and (c) balance check result

After selecting a smart card type, the transaction menu will be displayed and then select the "payment" button. In this payment menu, a list of registered partners will be displayed on the screen, and there is one button provided to enter the ID partner manually. Partner ID is set uniquely to distinguish between one partner to other partners. After selecting partners or entering ID manually as visualized in Fig. 17(a), next step is to enter the paid cost, then press the OK button. After that, the confirmation menu will display the total cost and the partner name. This menu is used to check whether the information entered is correct or not. If so, press the OK button.

Then insert the smart card in the slot provided if we use a contact type smart card. Once this step successfully, the password menu will be displayed. Enter the correct password, and the application will continue the payment process, which is to reduce the balance on the smart card with several values entered. The information menu will be displayed successfully, making a payment accompanied by the current balance value as visualized in Fig. 17(b). Also, the application will send transaction data to the server and print transaction proof as depicted in Fig. 17(c). 


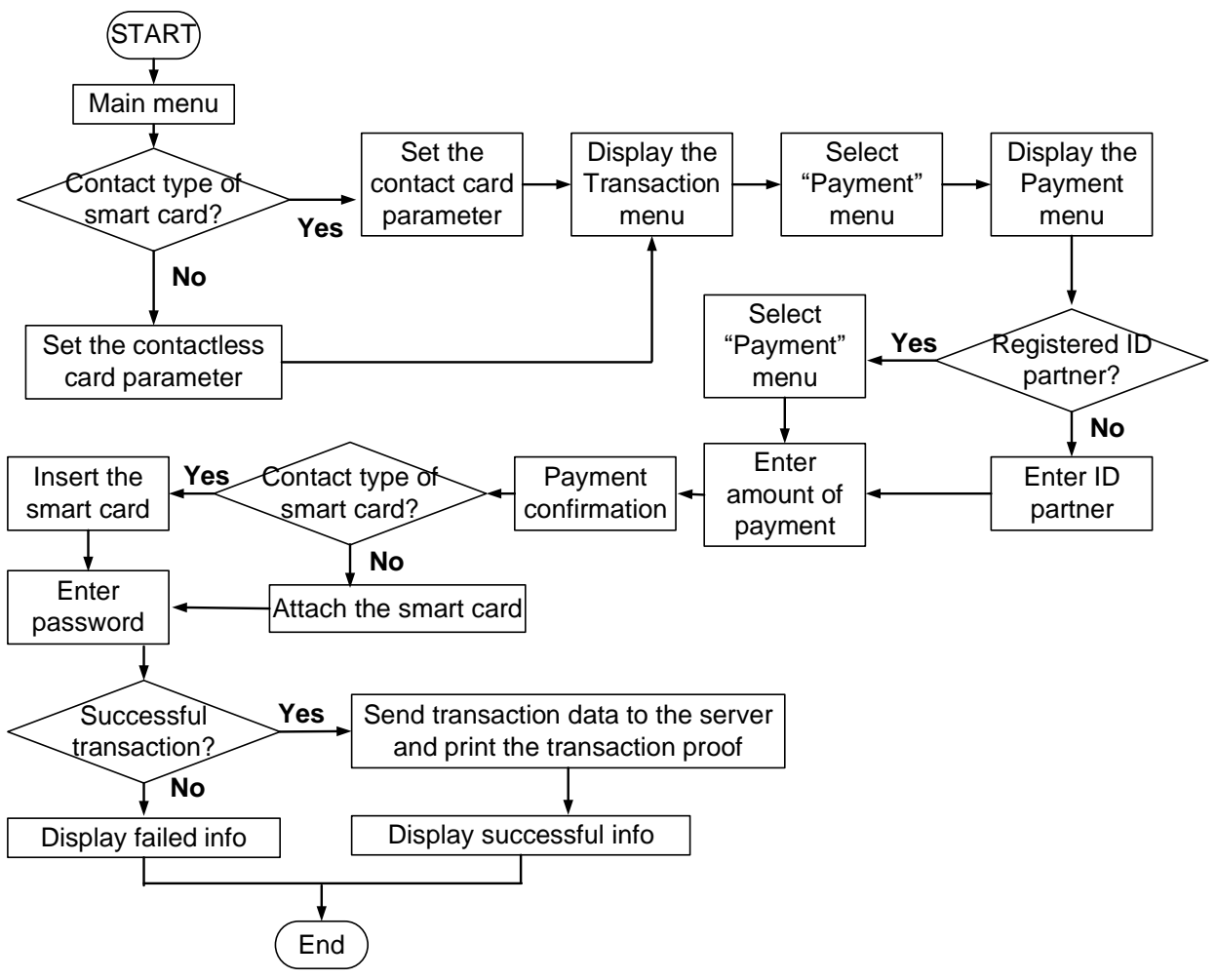

Fig. 16.Payment flow diagram

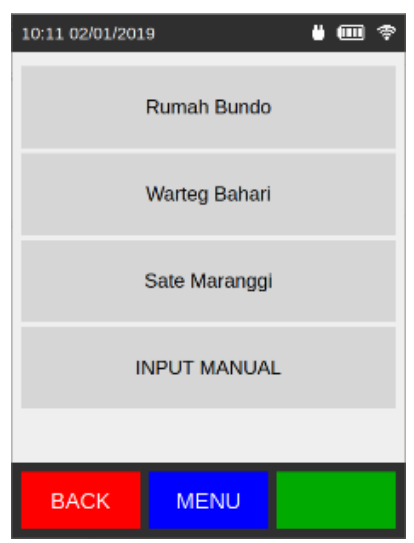

(a)

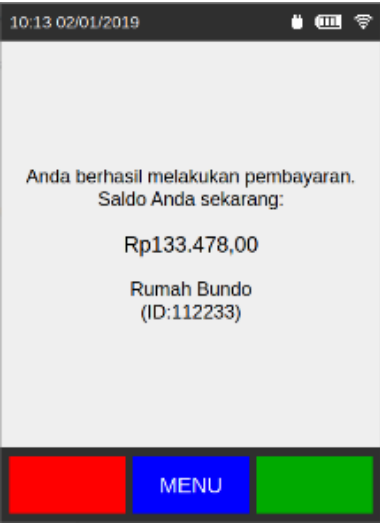

(b)

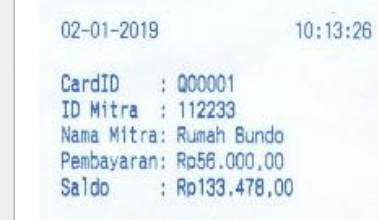

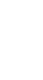

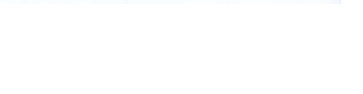

\section{(i)}

(c)

Fig. 17.Payment transaction menu: (a) list of partners, e.g., Rumah bundo, sate maranggi; (b) transaction result; (c) payment transaction print out 
Flowchart of top-up process is depicted in Fig. 18. Following are steps of the balance top-up: firstly, enter the main menu, then select the smart card type. After that, select the top-up transaction type to display the topup menu. In this menu, a button which contains the nominal contents is displayed, i.e., $5 \mathrm{~K}, 10 \mathrm{~K}, 25 \mathrm{~K}, 50 \mathrm{~K}$, 100K Rupiahs as visualized in Fig. 19(a). The user can choose the desired balance or refill the balance with tokens. A token is a unique code created by a server to fill a balance. The token input menu will be displayed when the "token" button is pressed. If the entered token is valid, we will see a confirmation menu on the application as shown in Fig. 19(b). The next step is to press "YES" button. Then, insert the smart card in the provided slot. If the process is successful, the information menu will be displayed and successfully refilled, along with the current balance value. Also, the application will send transaction data to the server and print successful top-up proof as shown in Fig. 19(c).

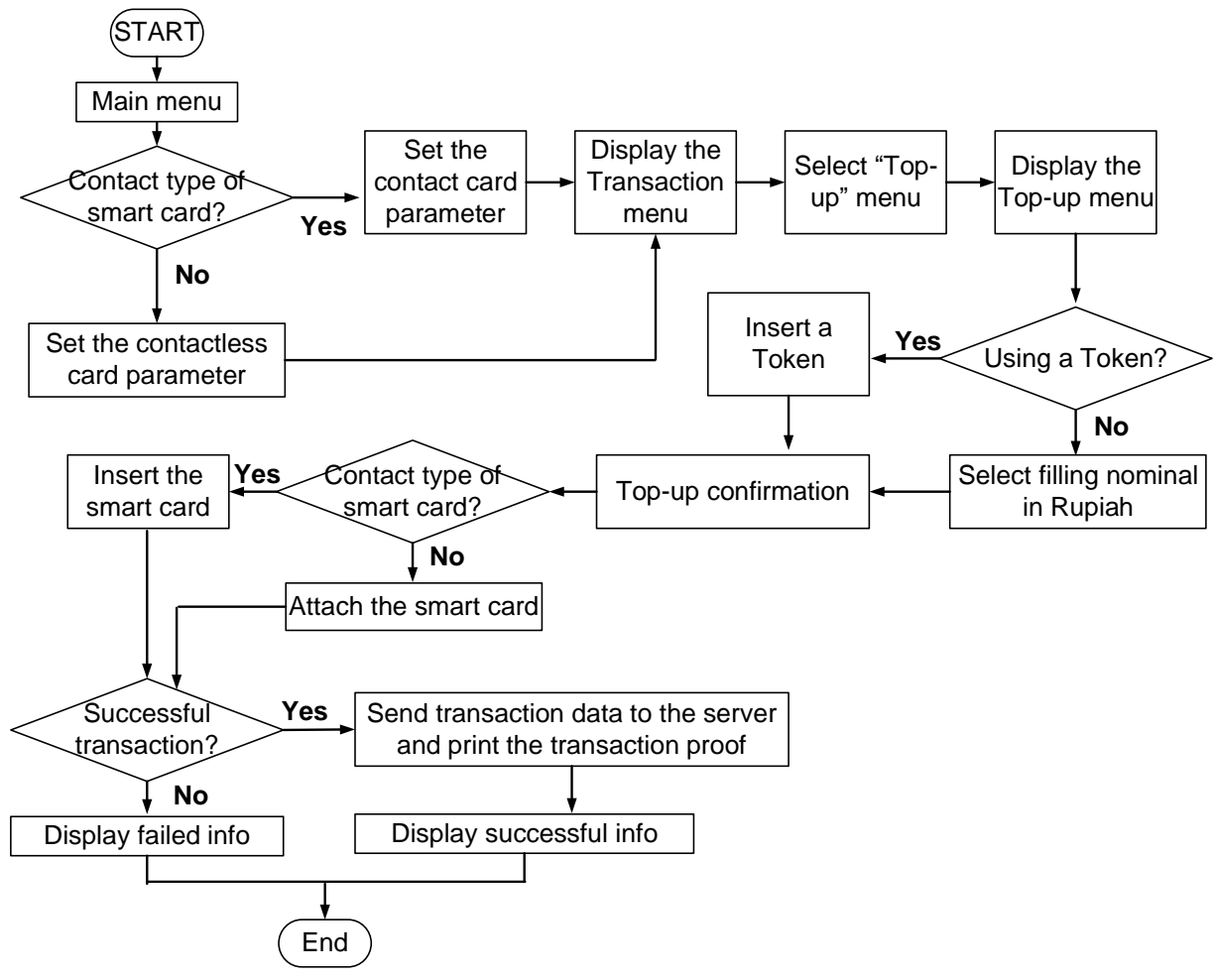

Fig. 18. Top-up flow diagram 


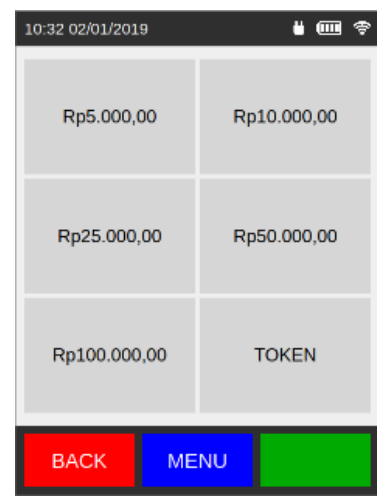

(a)

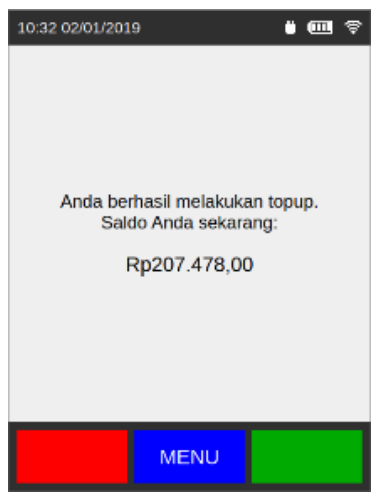

(b)

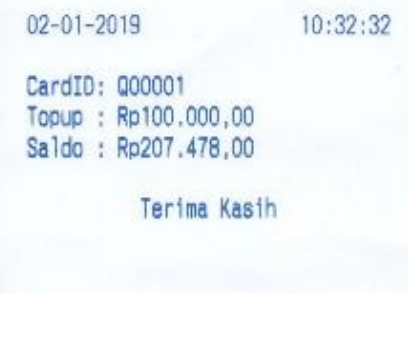

(c)

Fig. 19. Top-up transaction result: (a) the appearance of successful top-up on application; (b) proof of top-up activity

\section{Conclusion}

A Portable transaction device with dual interfaces (contact and contactless smart card) has been successfully developed using Raspberry as an application processor, ATMega328 as a smart card reader, and touchscreen as a user interface. In addition, transaction application can perform following tasks: balance check, top-up, and payment transaction. In this work, writing data on the smart card still uses the plain text. Therefore, it is still vulnerable to duplication. We do not compare our system's performance and to the available (existing) device, but compared to other devices on the feature aspect, our system can be operated in dual-mode and also can be connected to the own servers. Therefore, we expect that the transaction activity can be more secured. In further research, we will extend this paper with other major performance metrics (major properties parameters). We will apply the encryption feature as well as SAM mechanism for security.

\section{$5 \quad$ References}

[1] Bank Indonesia, "Statistik Sistem Pembayaran," [Online]. Available: https://www.bi.go.id/id/statistik/sistem-pembayaran/uangelektronik/contents/transaksi.aspx. [Accessed on January 11, 2019].

[2] Bank Indonesia, "Informasi Perizinan Penyelenggara dan Pendukung Jasa Sistem Pembayaran," [Online]. Available: https://www.bi.go.id/id/sistem-pembayaran/informasiperizinan/uang-elektronik/penyelenggara-berizin/Pages/default.aspx. [Accessed on January 11, 2019]. https://doi.org/10.21609/jsi.v13i1.465

[3] T. Adiono, R.I. Malinkas, A.C. Swastika, and S. Fuada, "Electronic Transaction Device Based on Contact Smart Card using Programmable SoC," Proc. of ICECOS, pp. 51-56, 2018. https://doi.org/10.1109/icecos.2018.8605217 
[4] A.C. Swastika and T Adiono, "Design and implementation of smart card interface device on Zynq-7000 system-on-chip," Proc. of ICITEE, July 2018. https://doi.org/10.1109/ici teed.2018.8534777

[5] P. Adole, J. M. Môm, and G.A. Igwue, "RFID Based Security Access Control System with GSM Technology,” Am. J. Eng. Res., Vol. 5(7), pp. 236-242, 2016.

[6] S. Thu, et al., "RFID-Based Monitoring and Access Control System for Parliamentary Campus," Int. J. Sci. Technol. Res., Vol. 5(6), pp. 98-101, 2016.

[7] M. Sangole, et al., "RFID Based Campus Management System: Access Control System," Int. J. Res. Eng. Appl. Manag., Vol. 3(2), 2017.

[8] G. Kaushal, et al., "RFID Based Security and Access Control System using Arduino with GSM Module,” Int. J. Eng. Technol., Vol. 2(2), pp. 309-314, 2015.

[9] U. Farooq, et al., "RFID Based Security and Access Control System," Int. J. Eng. Technol., Vol. 6(4), pp. 309-314, 2014.

[10] B. Yan, C. Yiyun, and M. Xiaosheng, "RFID technology applied in warehouse management system," Proc. of ISECS Int. Colloq. Comput. Commun. Control. Manag., Vol. 3, pp. 363-367, 2008.

[11] V. Suryawanshi, et al., “Automatic Toll Collection System Using QR Code,” Int. J. Eng. Comput. Sci., Vol. 9(2), pp. 61-66, 2017.

[12] S. R. Zope and P. M. Limkar, "RFID based Bill Generation and Payment through Mobile," Int. J. Comput. Sci. Netw., Vol. 1(3), pp. 2277-5420, 2012.

[13] S.-K. Noh, S.-R. Lee, and D. Y. Choi, "Proposed M-Payment System using Near-Field Communication and based on WSN-Enabled Location-Based Services for M-Commerce.," Int. J. Distrib. Sens. Networks, Vol. 2014, pp. 1-8, 2014. https://doi.org/10.1155/2014/ $\underline{865172}$

[14] A. J. Najm, "Developing a Payment System Contactless Smart Card," [Online]. Available: https://meu.edu.jo/libraryTheses/58734da8c19fa_1.pdf [Accessed on January 11, 2019].

[15] I.G. Purwanda, T. Adiono, S. Situmorang, F. Dawani, H.A. Samhany, and S. Fuada, "Prototyping Design of Low-Cost Bike Sharing System for Smart City Application," Proc. of IEEE Int. Conf. of ICT for Smart Society (ICISS), pp. 1-6, September 2017. https://doi. org/10.1109/ictss.2017.8288882

[16] T. Adiono, A. Alfaruq, and S. Fuada, "Hardware design of transaction device based on contact and contactless smart card," Proc. of the IEEE Asia Pacific Conf. on Circuit and Systems (APCCAS), November 2019. https://doi.org/10.1109/apccas47518.2019.8953181

\section{$6 \quad$ Authors}

Syifaul Fuada, received a B.A. in Electrical Engineering Education from Universitas Negeri Malang (UM), Indonesia, and a M.Sc. in Electrical Engineering option Microelectronics from the School of Electrical Engineering and Informatics, Institut Teknologi Bandung (ITB), Indonesia. He was with the University Center of Excellence at Microelectronics ITB from 2016-2018 as a main researcher. Now, he is with the Program Studi Sistem Telekomunikasi Universitas Pendidikan Indonesia (UPI) as a Lecturer. He has several achievements, such as receiving one of the 106 Indonesia Innovations by BIC-RISTEK DIKTI awards (2014) for Helm Charger product, a top of 10-student travel grant to the IEEE Asia Pacific Conference and Systems (APCCAS 2016) that was held in Jeju, South Korea, receiving one of 108 Indonesia Innovations by BIC-LIPI awards (2016) for Smart Home Product, receiving Best 
Paper Award from IEEE IGBSG 2018 that was held in Yi-Lan, Taiwan, receiving Best Paper Award from IEEE ICTRuDev 2018 that was held in Bali, Indonesia and receiving the Best paper award from a Scopus-indexed journal, i.e. International Journal of Online Engineering (iJOE), and receiving Best Paper Award from IEEE IGBSG 2019 that was held in Yichang, China. He is a member of IAENG and an associate editor of Jurnal INFOTEL (p-ISSN: 2085-3688, e-ISSN: 2460-0997). His research interests include analog circuit design and instrumentation, circuit simulation, engineering education, IoT, multimedia learning development and Visible Light Communication.

Akhmad Alfaruq, received a B.Eng. in Electrical Engineering from Telkom University, Indonesia, and he is with the M.Sc. in Electrical Engineering option Microelectronics from the School of Electrical Engineering and Informatics, Institut Teknologi Bandung (ITB), Indonesia. The author can be contact at alfaruq@ students.itb.ac.id. Jln. Ganesha No.10, Gd. Achmad Bakrie (LABTEK VIII) Lt. III, ITB campus, Bandung city 40132, West Java, Indonesia. Email: alfaruq@students.itb.ac.id

Trio Adiono received a B.Eng. in electrical engineering and an M.Eng. in microelectronics from Institut Teknologi Bandung, Indonesia, in 1994 and 1996, respectively. He obtained his Ph.D. in VLSI Design from the Tokyo Institute of Technology, Japan, in 2002. He holds a Japanese Patent on a High-Quality Video Compression System. He is now a Full professor and a senior lecturer at the School of Electrical Engineering and Informatics, and formerly serves as the Head of the Microelectronics Center, Institut Teknologi Bandung. His research interests include VLSI design, signal and image processing, VLC, smart cards, and electronics solution design and integration. tadiono@stei.itb.ac.id

Article submitted 2019-09-07. Resubmitted 2019-12-16. Final acceptance 2019-12-16. Final version published as submitted by the authors. 